\title{
UMA ANÁLISE CRÍTICA DOS IDEÁRIOS PEDAGÓGICOS CONTEMPORÂNEOS À LUZ DA TEORIA DE A. N. LEONTIEV
}

\author{
Nadia Mara Eidt*
}

RESUMO: O presente artigo objetiva demonstrar o alcance das "pedagogias do aprender a aprender" (DUARTE, 2001), uma vez que elas fundamentam as propostas educacionais no âmbito nacional e no internacional, na atualidade; bem como apresentar suas principais premissas, que mantêm sua filiação ao pragmatismo e ao irracionalismo e, no limite, submetem o desenvolvimento humano à ordem do capital. Tais proposições se contrapõem ao objetivo humanizador da educação escolar pressuposto na produção teórica do psicólogo soviético Alexis Leontiev. Como resultados, temos que, dessas produções, é possível extrair subsídios para o enfrentamento do processo de esvaziamento do ensino escolar e do papel do professor engendrado pelas referidas pedagogias. Além disso, pretende-se evidenciar a impossibilidade de aproximações entre as produções da psicologia histórico-cultural com outras correntes pedagógicas que estão a serviço da legitimação e do revigoramento da sociedade capitalista.

Palavras-chave: Pedagogias do Aprender a Aprender; Psicologia Histórico-Cultural; Educação Escolar; A. N. Leontiev.

\section{A CRITICAL ANALYSIS OF THE CONTEMPORARY PEDAGOGICAL IDEAS IN THE LIGHT OF A. N. LEONTIEV'S THEORY}

ABSTRACT: This article aims to demonstrate the extent of the "pedagogies of learning to learn" (DUARTE, 2001), since they support the current educational proposals nationally and internationally, and also present their main assumptions, which keep their membership to pragmatism and irrationalism, and in the limit, submit human development to the order of the capital. These propositions go against the goal of humanizing education's assumption in the theoretical production of the Soviet psychologist Alexis Leontiev. As a result, we concluded that, from these productions it is possible to extract subsidies to face the process of empting the school education and the teacher's role engendered by these pedagogies. Moreover, it is intended to highlight the impossibility of the approaches between historical-cultural psychology productions with other pedagogical currents aimed at the legitimacy and the reinvigoration of the capitalist society. Keywords: "Pedagogies of Learning to Learn"; Historical-Cultural Psychology; School Education; A. N. Leontiev.

\footnotetext{
* Doutoranda em Educação Escolar pela Universidade Estadual Paulista Júlio de Mesquita Filho (UNESP). E-mail: nadiaeidt@fc.unesp.br
} 


\section{Introdução}

O presente artigo objetiva demonstrar o alcance das "pedagogias do aprender a aprender" (DUARTE, 2001), as quais, na atualidade, fundamentam as propostas educacionais nos âmbitos nacional e internacional, bem como apresentar uma análise crítica das principais premissas que compõem tal ideário, as quais mantêm sua filiação ao pragmatismo e ao irracionalismo e, no limite, submetem o desenvolvimento humano à ordem do capital. Tais proposições se contrapõem ao objetivo humanizador da educação escolar pressuposto na produção teórica do psicólogo soviético Alexis Leontiev.

Com vista a atingir o objetivo proposto, o texto foi dividido em dois subitens. No primeiro, apresentaremos as correntes teóricas que compõem as pedagogias do aprender a aprender, sua pertinência no âmbito educacional na atualidade e, por fim, discutiremos, ainda que de maneira sintética, os traços essenciais de cada uma delas. No segundo subitem, demonstraremos como a psicologia de A. N. Leontiev se opõe às mencionadas pedagogias.

\section{As pedagogias do aprender a aprender: 0 que são e qual o seu alcance?}

O termo "pedagogias do aprender a aprender" foi cunhado por Duarte (2001) e pode ser definido como um termo "guarda-chuva", por reunir os traços essenciais de diferentes correntes pedagógicas, entre elas a Escola Nova, o Construtivismo, a Pedagogia das Competências e os estudos na linha do Professor Reflexivo.

O "aprender a aprender" tem sido considerado por ampla parcela dos intelectuais da educação da atualidade como um verdadeiro símbolo das posições pedagógicas mais inovadoras, progressistas e, portanto, sintonizadas com o que seriam as necessidades dos indivíduos na chamada "sociedade do conhecimento". Isso pode ser verificado tanto na política educacional internacional quanto na nacional.

No que se refere ao primeiro aspecto, Miranda (1997) realizou um estudo de distintos documentos de organismos internacionais vigentes na década de 90 do século XX sobre as políticas educacionais para a 
América Latina. Esses documentos expressam um "novo paradigma" de conhecimento que deve vigorar nos países latinos, visando a assegurar sua competitividade no mercado internacional. Entre esses documentos, vale mencionar o da Comissão Econômica para América Latina e Caribe (CEPAL), em parceria com a Unesco, intitulado "Educación e conocimiento: eje de la transformación productiva con equidad", o qual preconiza que

a acumulação de conhecimentos técnicos implica uma complementação entre criação de conhecimento, inovação e difusão. Para desenvolver e utilizar plenamente as novas tecnologias, resultam imprescindíveis alguns processos fundamentais de aprendizagem, em particular as modalidades de aprendizagem mediante a prática (learning-by-doing), mediante o uso de sistemas complexos (learning-by-using) e mediante a interação entre produtos e consumidores (learning-by-interacting) (CEPAL/UNESCO, 1992, p. 31 apud MIRANDA, 1997, grifos nossos).

Destarte, esse documento oficial parte da premissa da aprendizagem na e pela prática, evidenciando o revigoramento do ideário deweyano e piagetiano na educação do final do século XX. Como será demonstrado no próximo item, não causa surpresa que o primado da experiência se mantenha como grande inovação pedagógica e que, por isso, jamais possa ser considerado como "assunto do século passado".

A atualidade do lema aprender a aprender também pode ser verificada no "Relatório da Comissão Internacional para a Educação do Século XXI”, organizada por Jacques Delors (1998). Segundo o referido documento, cabe à educação básica oportunizar tanto a preparação para a vida quanto condições para aprender a aprender:

(...) em todos os países, mesmo naqueles em que todas as crianças estão inscritas no ensino básico, é preciso prestar particular atenção à qualidade do ensino. A educação básica é, ao mesmo tempo, uma preparação para a vida e o melhor momento para aprender a aprender (DELORS, 1998, p. 127).

Uma das premissas centrais do referido documento é a defesa da educação ao longo de toda a vida. Esta, por sua vez, baseia-se em quatro pilares: aprender a conhecer, aprender a fazer, aprender a viver juntos, aprender a ser, conforme segue: 
- Aprender a conhecer, combinando uma cultura geral, suficientemente vasta, com a possibilidade de trabalhar em profundidade um pequeno número de matérias. O que também significa: aprender a aprender, para beneficiar-se das oportunidades oferecidas pela educação ao longo de toda a vida.

- Aprender a fazer, a fim de adquirir, não somente uma qualificação profissional mas, de uma maneira mais ampla, competências que tornem a pessoa apta a enfrentar numerosas situações e a trabalhar em equipe. Mas também aprender a fazer, no âmbito das diversas experiências sociais ou de trabalho que se oferecem aos jovens e adolescentes, quer espontaneamente, fruto do contexto local ou nacional, quer formalmente, graças ao desenvolvimento do ensino alternado com o trabalho.

- Aprender a viver juntos desenvolvendo a compreensão do outro e a percepção das interdependências - realizar projetos comuns e preparar-se para gerir conflitos - no respeito pelos valores do pluralismo, da compreensão mútua e da paz.

- Aprender a ser, para melhor desenvolver a sua personalidade e estar à altura de agir com cada vez maior capacidade de autonomia, de discernimento e de responsabilidade pessoal. Para isso, não negligenciar na educação nenhuma das potencialidades de cada indivíduo: memória, raciocínio, sentido estético, capacidades físicas, aptidão para comunicar-se (DELORS, 1988, p. 101-102)

Por fim, no que se refere à política educacional brasileira, a análise dos documentos oficiais para a formação de professores, tais como as "Diretrizes Curriculares Nacionais para a Formação de Professores da Educação Básica - Parecer n. 09/2001” (BRASIL, 2002a) e os “Referenciais para Formação de Professores” (BRASIL, 2002b), revela a importância desse ideário nas políticas de formação de professores. Esses documentos têm como seus principais fundamentos teóricos a pedagogia das competências e a teoria do professor reflexivo, e evidenciam que a formação de professores é um processo contínuo, que visa ao desenvolvimento de competências necessárias ao exercício do trabalho docente:

As competências tratam sempre de alguma forma de atuação, só existem "em situação" e, portanto, não podem ser aprendidas apenas no plano teórico nem no estritamente prático. A aprendizagem por competências permite a articulação entre teoria e prática e supera a tradicional dicotomia entre essas duas dimensões, definindo-se pela capacidade de mobilizar múltiplos recursos numa mesma situação, entre os quais os conhecimentos adquiridos na reflexão sobre as questões pedagógicas e aqueles construídos na vida profissional e pessoal, para responder às diferentes demandas das situações de trabalho (BRASIL, 2002a, p. 30). 
E ainda:

Competências, como entendida nestes documentos, refere-se à capacidade de mobilizar múltiplos recursos, entre os quais os conhecimentos teóricos e experiências da vida pessoal e profissional, para responder às diferentes demandas das situações de trabalho. Apoia-se, portanto, no domínio de saberes, mas não apenas de saberes teóricos, e refere-se à atuação em situações complexas (BRASIL, 2002b, p. 61).

Entendemos que esses exemplos são suficientes para demonstrar a extensão e a importância de tal ideário no cenário educacional atual. Resta explicitarmos, então, quais são os traços essenciais dessas diferentes correntes teóricas, tarefa que realizaremos a seguir.

\subsection{A Escola Nova}

A produção pedagógica do filósofo americano John Dewey (1859-1952), principal representante do movimento escolanovista, deve ser entendida como decorrente das mudanças econômicas e sociais na passagem do século XIX para o XX, no caso, principalmente vinda no bojo da Segunda Revolução Americana, impregnada pelo advento da administração científica do trabalho, preconizada por Frederik Taylor (1856-1915) e Henry Ford (1863-1947). Nessa direção, a imbricação entre o processo produtivo e a prática educativa ancorada na filosofia pragmatista deweyana aponta a necessidade da construção de um novo homem, engendrada, em grande medida, nos bancos escolares. Não obstante, se, por um lado, com a revolução industrial americana, o acesso à escolarização se amplia - já que o advento da industrialização, nos Estados Unidos, demandava que os operários tivessem acesso a uma qualificação geral mínima, que contemplasse os códigos formais, exigência suprida pelo currículo da escola elementar -, por outro, faz-se necessário fiscalizar sistematicamente o conteúdo científico ou clássico a que essa população teria acesso. Como procuraremos mostrar ao longo do texto, o controle do conhecimento do trabalhador continua presente nas pedagogias contemporâneas, a despeito do seu aparente discurso revolucionário.

A configuração desse processo de trabalho - o modelo taylorista-fordista - permitiu, por um lado, simplificar as operações, eliminar os movimentos desnecessários, lentos e ineficientes, e, por outro lado, encontrar o movimento certo e mais rápido em todos os ofícios (SAUL, 
2004; MERLO; LAPIS, 2007). Além disso, com a reestruturação produtiva, o trabalho foi decomposto em parcelas cada vez mais elementares e simplificadas, em atividades parceladas, repetitivas e carentes de sentido, expropriando o indivíduo da capacidade criativa. "Estava consolidandose, no capitalismo, uma radical separação entre o saber e o fazer; entre a concepção, o planejamento e a execução; entre o trabalho manual dos operários e o trabalho intelectual das gerências" (MERLO; LAPIS, 2007, p. 62-63). Como consequência, houve um processo de esvaziamento do trabalho, como bem denuncia Gramsci (2001, p. 266):

Taylor expressa, com brutal cinismo o objetivo da sociedade americana: desenvolver em seu grau máximo, no trabalhador, comportamentos maquinais e automáticos, quebrar a velha conexão psicofísica do trabalho profissional qualificado, que exigia certa participação ativa da inteligência, da fantasia, da iniciativa do trabalhador e reduzir as operacões produtivas apenas ao seu aspecto físico maquinal (GRAMSCI, 2001, p. 266, grifos nossos).

Atendendo, portanto, à demanda imposta pelo capital, os pressupostos escolanovistas se opõem à escola tradicional, que tem como característica a centralidade da instrução (formação intelectual) e do professor, cuja tarefa é transmitir os conhecimentos acumulados pela humanidade, segundo uma gradação lógica, cabendo aos alunos aprender os conteúdos que lhes são transmitidos.

Por sua vez, as correntes renovadoras, desde seus precursores como Rousseau, Pestalozzi e Froebel, chegando ao movimento da Escola Nova e, posteriormente, como veremos, o construtivismo -, trariam à tona a questão de como o aluno aprende. Elas preconizam que a pedagogia deve abandonar a perspectiva tradicional, centrada no professor e na transmissão de conteúdos, uma vez que tal perspectiva impediria “(...) a criança de descobrir a verdade por si mesma” (PARRATY-DAYAN; TRYPHON apud FACCI, 2004, p. 83), além de atribuir ao aluno um comportamento passivo no processo de ensino-aprendizagem. Tais correntes passam da centralidade do professor e do conhecimento científico para o aluno, e seus interesses centram-se, portanto, sempre na questão de como aprender, isto é, em teorias da aprendizagem, em sentido geral (SAVIANI, 2005). Interagindo entre si e com o professor, os alunos realizam a própria aprendizagem na e pela experiência: 
Foi tão inevitável quanto foi direta e certa a sua ruptura radical com o material isolado e estéril que constituía o fulcro, o sustentáculo da educação velha. Além disso, a substituição das matérias pela experiência importava em se ter em conta campo muito mais amplo, cujo conteúdo varia de lugar para lugar e de tempo em tempo (DEWEY, 1976, p. 80, grifos nossos).

Como podemos verificar no excerto anterior, a experiência se opõe, de forma contundente, ao ensino baseado na transmissão de conteúdos por parte do professor. Isso porque, para os autores escolanovistas, na escola tradicional haveria uma cisão entre o saber acumulado por meio da "experiência prática", adquirida antes do ingresso da criança na escola, e as aprendizagens escolares, que se constituem em um novo mundo, o "mundo dos livros", sinônimo de "um saber estranho":

A entrada da criança na escola marca uma trágica solução de continuidade entre o mundo de sua "experiência prática" onde viveu até então e que constitui todo o seu saber, e esse novo mundo de saber imposto e dos livros, onde pretendemos introduzi-la. Nossa escola moderna é o instrumento pelo qual o Estado se esforça por substituir tão cedo quanto possível o saber da experiência, que só se desenvolve lentamente, pela transmissão de um saber estranho (BLOCH, 1951, p. 15).

Destarte, no lugar dos exercícios repetitivos propostos pela disciplina formal, Dewey (1976, p. 16) preconiza a experiência prática como condição primeira para a consecução de uma "educação genuína”. O referido autor (1959a, p. 53) é enfático ao negligenciar o papel do conhecimento científico na formação do pensamento dos escolares: "Convém, outrossim, repelir a noção análoga de que certas matérias são essencialmente intelectuais, possuindo, por isso, um poder quase mágico para adestrar a faculdade do pensamento". O autor afirma ainda que seria um equívoco acreditar que "(...) o espírito se enriquece com novos conhecimentos, como também, assimilando as definições lógicas já formuladas e as generalizações, adquirirá também hábitos lógicos" (DEWEY, 1959a p. 87-88).

Não obstante, nessa nova perspectiva, qual o papel atribuído ao professor? Este se limita a acompanhar os alunos, auxiliando-os em seu próprio processo de aprendizagem, como pode ser verificando nesta passagem de Dewey (1959a, p. 43): “Aprender é próprio do aluno: só ele aprende, e por si; portanto, a iniciativa lhe cabe". Como consequência, na atividade educativa, "o professor é um aluno e o aluno é, sem saber, um 
professor - e, tudo bem considerado, melhor será que, tanto o que dá como o que recebe a instrução, tenham ao menos consciência possível de seu papel" (DEWEY apud Saviani, 2005, p. 2). A partir desse postulado, Valdemarim afirma que:

(...) na medida em que o conhecimento tem como ponto de partida a experiência já existente ou a ser realizada pelo próprio aluno, o docente participa das atividades em condiçoes de igualdade com ele e não mais como aquele que detém o conhecimento e o método de gerar a aprendizagem dirigindo o processo (VALDEMARIN apud SAVIANI, 2005, p. 3, grifos nossos).

Como seria organizado o ensino se o professor pode ser aluno, enquanto o aluno pode se tornar professor? Para que isso seja possível, não deve haver uma pessoa mais desenvolvida na relação - que tenha se apropriado do conhecimento socialmente produzido ao longo do processo histórico -, mas pessoas cujos domínios do conhecimento seriam equivalentes. Com isso, no limite, coloca-se em xeque não apenas a carreira docente, mas também o papel social da escola enquanto instituição responsável pela socialização do conhecimento humano a todos os indivíduos.

É com Dewey que vemos nascer o lema do aprender a aprender, tão propagado pelas pedagogias contemporâneas como uma inovação no cenário pedagógico.

$\mathrm{O}$ aprender a prática de um ato, quando não se nasce sabendo-o, obriga a aprender-se a variar seus fatores, a fazer-se combinações sem conta destes, de acordo com a variação das circunstâncias. E isso traz a possibilidade de um contínuo progresso, porque, aprendendo-se um ato, desenvolvem-se métodos bons para outras situações. Mais importante ainda é que o ser humano adquire o hábito de aprender. Aprende a aprender (DEWEY, 1959b, p. 48, grifos nossos).

Como pode ser verificado na passagem que segue, o lema aprender a aprender surge com toda a sua força, uma vez que se faz necessário adaptarse às demandas do processo produtivo para não ser por ele "esmagado":

Uma sociedade móvel, cheia de canais distribuidores de todas as mudanças ocorridas em qualquer parte, deve tratar de fazer que seus membros sejam educados de modo a possuírem iniciativa individual e adaptabilidade. Se não fizer assim, eles serão esmagados pelas mudanças em que se virem envolvidos e cujas associações ou significações eles não percebem (DEWEY, 1959b, p. 94).

Educação em Revista | Belo Horizonte | v.26 | n.02 | p.157-188 | ago. 2010 
Dewey (1959b) não deixa dúvidas sobre a necessidade da constante adaptabilidade do indivíduo à lógica do capital, proposição nem sempre verificada em autores contemporâneos das "pedagogias do aprender a aprender", que se utilizam de recursos bastante sedutores para encobrir a estreita relação entre a prática educativa e as forças produtivas.

Destarte, em síntese, o escolanovismo se opõe, de forma clara, à transmissão-apropriação de conteúdos escolares considerados saberes estranhos, portanto, impossíveis de integrar a personalidade das crianças em desenvolvimento. A formação escolar deveria ocorrer de forma semelhante ao modo como as crianças aprendem a construir seus conhecimentos antes de ingressar na escola, ou seja, por meio da experiência prática. O professor, nessa perspectiva teórica, não tem o compromisso de ensinar - termo banido do vocabulário escolanovista -, mas, sim, de servir de um modelo de imitação para as crianças, fornecendo, assim, elementos para a constituição de sua personalidade. É importante frisar que esse processo de imitação da criança em relação aos adultos em nada difere da observação que a criança realiza junto aos objetos naturais. Verifica-se, portanto, a indistinção entre fenômenos naturais e sociais, especificamente humanos. Outra ressalva consiste no fato de que a imitação tem como finalidade última a adaptação ao meio.

A imitação é um dos meios (...) graças aos quais a atividade do adulto provê estímulos tão interessantes, variados, complexos e novos que o pensamento progride rapidamente. (...) a criança observa as pessoas como observa os acontecimentos naturais, para receber novas sugestões quanto ao meio de realizá-lo. Escolhe alguns dos processos que viu empregar, experimenta-os pessoalmente e acha-os apropriados ou não; confirma-se ou não a sua opinião sobre o valor deles e continua, assim, a preparar, a adaptar, a procurar provas, até que o fim desejado seja atingido (DEWEY, 1959a, p. 206, grifos nossos).

A relação entre indivíduo e sociedade é entendida, nesta abordagem teórica, de forma naturalizada, já que prevalece a continuidade entre o homem e a natureza:

A morada do homem é a natureza; a execução de seus instintos e objetivos depende das condições naturais. (...) Esta filosofia tem a sansão de toda a teoria do desenvolvimento biológico, que mostra serem o homem e a natureza um todo contínuo e não ser ele um estrangeiro que penetre de fora nos processos dessa última (DEWEY, 1959b, p. 314-315). 
Dewey influenciou decisivamente o biólogo genebrino Jean Piaget (1896-1980), fundador do Construtivismo, questão da qual trataremos a seguir.

\subsection{Construtivismo}

Se, como evidenciamos no item anterior, as teorias educacionais não são criadas "no abstrato", mas são, em grande medida, determinadas pela necessidade imposta pelo capital, então a obra de Jean Piaget deve ser entendida à luz do modelo de produção flexível, também conhecido como toyotismo, que tem seis princípios centrais: 1) A produção torna-se vinculada à demanda, de modo a atender as especificidades e exigências do mercado consumidor; com isso, a produção caracteriza-se pela variabilidade e pela diversidade, o que distingue, de forma bastante expressiva, o toyotismo do taylorismo e do fordismo; 2) A produção ancora-se no pressuposto do trabalho em equipe; 3) Em virtude da produção flexível, o operário não é responsável por apenas uma máquina, mas chega a operar até cinco; 4) A produção é baseada no método just in time, ou seja, visa ao aproveitamento máximo do tempo no processo produtivo, bem como no Kanban, um sistema de códigos (placas ou senhas) indicativos da necessidade de reposição do estoque; 5) A estrutura é horizontalizada diferente da fordista, que é verticalizada, o que significa que, se, no fordismo, $75 \%$ da produção são realizados no interior da fábrica, no toyotismo, esse percentual cai para $25 \%$, ou seja, apenas os processos centrais são realizados no interior da fábrica, sendo o restante terceirizado para outras empresas; 6) São organizados círculos de controle de qualidade (CCQs), em que grupos de trabalhadores são “(...) instigados pelo capital a discutir seu trabalho e desempenho" (ANTUNES, 2005a, p. 55, grifos do autor), visando ao aumento da produtividade da empresa. Essa é, segundo o referido autor, uma importante estratégia, em que o capital se apropria do saber intelectual e cognitivo do trabalhador, outrora desprezado pelo fordismo (ANTUNES, 2005a).

O colapso do taylorismo/fordismo demandou a reorganização da base material, culminando em um avanço tecnológico, expresso pela substituição da mecanização pela automação. Esse processo, de base microeletrônica, caracterizou-se pela transferência das operações intelectuais para as máquinas. Sob a égide do toyotismo, o indivíduo “(...) faz e pensa para o capital" (ANTUNES, 1997, p. 74). 
Importante esclarecer que o processo de expropriação da maioria dos trabalhadores torna-se ainda mais intenso, pois, além de objetivar sua inteligência no maquinário tecnocientífico, há sobrecarga da mão de obra, concomitantemente à redução do tempo de execução da atividade produtiva:

Como o capital não pode eliminar o trabalho vivo do processo de mercadorias, sejam elas materiais ou imateriais, ele deve, além de incrementar sem limites o trabalho morto corporificado no maquinário tecnocientífico, aumentar a produtividade do trabalho de modo a intensificar as formas de extração do sobre-trabatho em tempo cada vez mais reduzido. Tempo e espaço se convulsionam nesta nova fase dos capitais. A redução do proletariado taylorizado, a ampliação do trabalho intelectual abstrato e nas plantas produtivas de ponta e a ampliação generalizada de novos proletários precarizados e terceirizados da 'era da empresa enxuta' são fortes exemplos do que acima aludimos (ANTUNES, 2002, p. 40, grifos do autor).

Antunes (1997) não deixa dúvidas sobre as consequências dessa forma de reorganização, para os trabalhadores:

(...) de um lado, verificou-se uma desproletarização do trabalho industrial, fabril, manual, especialmente nos países de capitalismo avançado. Em outras palavras, houve uma diminuição da classe operária industrial tradicional. Mas, paralelamente, efetivou-se uma expressiva terceirização do trabalho, a partir da enorme ampliação do assalariamento no setor de serviços, verificou-se uma significativa heterogenerização do trabalho, expressa através da crescente incorporação do contingente feminino no mundo operário. Pode-se presenciar também um significativo processo de subproletarização intensificada, presente na expansão do trabalho parcial, precário, que marca a sociedade dual no capitalismo avançado (ANTUNES, 1997, p. 63-64).

Antunes (2005b) ensina ainda que a diminuição da hierarquia no interior da fábrica, consequência da diminuição do despotismo fabril, e a defesa emblemática da "participação" do trabalhador no processo produtivo devem ser entendidas como necessidade de criação e valorização do próprio capital. Assim sendo, essas "singularidades" não são capazes de suprimir o estranhamento incrementado pelo modelo toyotista; ao contrário, verifica-se que esse processo de estranhamento entre indivíduo e gênero humano se intensifica em diversos segmentos da classe trabalhadora: 
O estranhamento próprio do toyotismo é aquele dado pelo "envolvimento cooptado", que possibilita ao capital apropriar-se do saber e do fazer do trabalho. Este, na lógica da integração toyotista, deve pensar e agir para o capital, para produtividade, sob a aparência da eliminação efetiva do fosso existente entre elaboração e execução no processo de trabalho. Aparência porque a concepção efetiva dos produtos, a decisão do que e de como produzir não pertence aos trabalhadores. O resultado do processo de trabalho corporificado no produto permanece alheio e estranho ao produtor, preservando, sob todos os aspectos, o fetichismo da mercadoria. A existência de uma atividade autodeterminada, em todas as fases do processo produtivo, é uma absoluta impossibilidade sob o toyotismo, porque seu comando permanece movido pela lógica do sistema produtor de mercadorias. Por isso pensamos que se possa dizer que, no universo da empresa da era da produção japonesa, vivencia-se um processo de estranhamento do ser social que trabalha, que tendencialmente se aproxima do limite. Neste preciso sentido é um estranbamento pós-fordista (ANTUNES, 2005b, p. 42, grifos do autor).

Se, no taylorismo/fordismo, a relação entre aqueles que vendem sua força de trabalho e os proprietários dos meios de produção era mais "despótica", a empregada no toyotismo é mais "consensual", "envolvente", participativa, essencialmente mais "manipulatória". Esses traços alteram a aparência dessa relação, na medida em que o toyotismo se utiliza, por um lado, de um padrão produtivo tanto organizacional quanto tecnologicamente avançado, e, por outro, da introdução, em larga escala, no processo produtivo e de serviços, mas não a sua essência, porquanto a divisão social do trabalho, a propriedade privada e a exploração da maisvalia do trabalhador se mantêm inalterados como traços fundamentais do capitalismo. Por essa razão, Antunes (2005b) caracteriza o toyotismo como um período de estranhamento "pós-fordista".

Apresentaremos a seguir os principais pressupostos do construtivismo, para, posteriormente, demonstrar que esse referencial não foi produzido no abstrato, mas pretende colaborar na construção de um novo homem, capaz de atender às novas demandas do toyotismo.

Piaget recupera os postulados escolanovistas, na medida em que se opõe à escola tradicional, trazendo à tona a questão de como o aluno aprende. Ambas as teorias preconizam que a pedagogia deve abandonar a centralidade no professor e na transmissão de conteúdos ${ }^{1}$, empregando os métodos ativos, cujo princípio fundamental consiste no fato de que "(...) compreender é inventar, ou reconstruir através da reinvenção", se o que se pretende é "moldar indivíduos capazes de produzir e criar, e não apenas repetir" (PIAGET, 1977, p. 20). Nessa perspectiva, confere-se “(...) 
especial relevo à pesquisa espontânea da criança ou do adolescente $e$ exigindo-se que toda a verdade a ser adquirida seja reinventada pelo aluno, ou pelo menos reconstruida e não simplesmente transmitida" (PIAGET, 1977, p. 18, grifos nossos).

Nessa direção, Piaget (1977) chama a atenção para dois componentes fundamentais da educação científica. O primeiro consiste na possibilidade de os alunos desenvolverem uma "atividade autêntica", de forma que "(...) sejam chamados a reconstruir e em parte reinventar as verdades que é preciso assimilar e, sobretudo, uma prática individual do espírito experimental e dos métodos que o mesmo comporta" (PIAGET, 1977, p. 27-28). Tal pressuposto é coerente com a ideia de que o indivíduo constrói o conhecimento e a verdade na e pela atividade prática. Tal ideia carrega em si a secundarização da razão, culminando no irracionalismo.

Outro aspecto irracionalista presente na obra de Piaget já foi analisado por Duarte (2001), a saber, a atitude negativa de Piaget para com a filosofia e sua defesa da neutralidade da ciência, que seria despida de ideologias. Também, como mostra Duarte (2001), Vigotski já assinalara que Piaget procurava apresentar os dados empíricos como se eles dispensassem o recurso à teorização, o que é claramente uma atitude irracionalista ${ }^{2}$.

Piaget atualiza a proposição deweyana e afirma: "O ideal da educação não é aprender ao máximo, maximizar os resultados, mas antes de tudo, é aprender a aprender; é aprender a se desenvolver e aprender a continuar a se desenvolver depois da escola" (PIAGET, 1977, p. 225). O aprender a aprender converte-se, assim, na premissa central para a adaptação do indivíduo às constantes mudanças do modelo de acumulação flexível. Em outras palavras, o indivíduo precisa estar em condições de aprender continuamente fragmentos de conhecimentos que possibilitem a realização de múltiplas tarefas no interior do processo produtivo.

Nessa direção, cabe aqui analisar a discussão feita por Piaget a respeito da heteronomia $\mathrm{x}$ autonomia moral e intelectual, bem como do papel da escola e do professor nesse processo. Piaget (1998b, p. 111) é enfático em apontar o papel desastroso exercido pelo professor na escola tradicional, atuando por meio da coerção e não favorecendo, assim, o desenvolvimento da autonomia intelectual: "A única relação social que a escola tradicional conhece é a relação exclusiva da criança com o professor, ou seja, a relação entre um inferior que obedece passivamente e um 
superior que encarna a verdade definitiva e a própria lei moral”. A coerção engendra na criança uma "obrigação imperativa", ou seja, o respeito incontestável às regras e decisões, e tem como consequência a não-superação da heteronomia em direção à autonomia intelectual e moral. Piaget propõe um novo método baseado no "self-government"; aqui, a coerção dá lugar à cooperação, pois a igualdade, seja ela de fato ou de direito, supera a autoridade. Em síntese, portanto,

enquanto a coerção permanecer exterior ao espírito, as condições são desfavoráveis tanto para o desenvolvimento da personalidade como para o da solidariedade. Estando submetido a uma coerção vinda de fora, o indivíduo não atinge a autonomia da disciplina interior que caracteriza a personalidade e, por falta de interiorização das regras, ele só sai aparentemente de seu egocentrismo, em vez de sentir-se solidário a todos. Ao contrário, a disciplina própria ao self-government é ao mesmo tempo fonte de autonomia interior e verdadeira solidariedade (PIAGET, 1998a, p. 126).

Nessa perspectiva, a educação anuncia a possibilidade de desenvolver nos indivíduos a cooperação e a solidariedade, pois, em virtude da diminuição do egocentrismo intelectual e moral, os indivíduos seriam capazes de analisar os diversos pontos de vista existentes e colaborar para o desenvolvimento de um verdadeiro projeto coletivo. Essas ideias parecem bastante coerentes com a proposição toyotista do trabalho organizado em equipe, em que o trabalhador deve desempenhar várias funções, diferentemente dos movimentos repetitivos e particulares do taylorismo e do fordismo. No interior desses grupos de trabalho, organizam-se "Círculos de Controle de Qualidade" ou CCQs, nos quais os trabalhadores devem discutir seu trabalho e seu desempenho, visando a melhorar a produtividade da empresa. A valorização das opiniões dos funcionários constitui-se em um novo modo de o capital se apropriar do saber intelectual do operário, outrora desprezado pelo taylorismo (ANTUNES, 2005a).

Visando a explicitar tanto a materialidade quanto a contradição vigente no modelo de produção atual - o toyotismo -, tem-se que um dos seus traços essenciais consiste no acirramento das condições de exploração da força de trabalho, que se expressa, entre outras formas, por meio da "empresa enxuta", modelo a ser seguido, uma vez que emprega um número reduzido de trabalhadores, que, por outro lado, alcançam largas 
margens de produtividade (ANTUNES, 2005a). Nessa direção, o apelo emocional para "vestir a camisa da empresa", fazendo dela uma extensão da família de cada trabalhador, conforma-se, contraditoriamente, com a necessidade presente em cada uma das várias unidades que compõem a totalidade da empresa, qual seja, tornar-se diretamente responsável pelo sucesso ou pelo fracasso da equipe de trabalho, gerando, assim, um clima de fiscalização permanente de cada um sobre todos os outros (SOUZA, 2006).

Nesse sentido, o ideário da solidariedade tem, em nosso entender, importante papel ideológico, qual seja, o de escamotear a crescente exploração vivida pelo trabalhador nessa "nova" lógica produtiva:

Na defesa de um humanismo (ingênuo), ou melhor, na educação para a convivência (pacífica) com o diferente, é retomada a exigência da tolerância, agora como uma obrigação escolar antes não lembrada. (...) No apoio ao pluralismo (sem nenhuma referência à realidade concreta), alianças e parcerias são apresentadas enquanto descarnadas de interesses de grupos ou de interesses privados. A solidariedade, em sua convocação educacional atual, é representada como virtude bumana tão descarnada do mundo dos homens que mais parece um convite à caridade cristã, exercida à época que antecedeu a propriedade privada (NAGEL, 2002, p. 8, grifos nossos).

Como esclarece Tonet (2005), Marx pontuou importantes elementos da subjetividade na era do capital e, entre eles está a solidariedade:

Cada indivíduo é, como diz Marx (1991), uma mônada isolada que se choca contra todas as outras na busca por sua realização. Daí por que a sociedade é vista como sendo, e realmente é, composta por indivíduos competitivos, opostos entre si, cada um procurando satisfazer seus interesses e tendo os outros como inimigos e não como companheiros. Daí por que a solidariedade tem que se apresentar e só pode apresentar-se nesta forma de sociabilidade, necessariamente, como caridade, como boa vontade, como assistência, ou então, como união na luta por uma nova forma de sociabilidade (TONET, 2005, p. 69).

Voltando à discussão dos pressupostos teóricos construtivistas, no que se refere ao papel do professor, Piaget (1977) defende que ele deve ser um pesquisador, construindo um conjunto de problemas úteis por meio dos quais a criança exercerá sua capacidade de reflexão: 
(...) é evidente que o educador continua indispensável, a título de animador, para criar as situações, e armar os dispositivos iniciais capazes de suscitar problemas úteis à criança, e para organizar, em seguida, contraexemplos que levem à reflexão e obriguem ao controle das situações demasiado apressadas: o que se deseja é que o professor deixe de ser apenas um conferencista e que estimule a pesquisa e o esforço, ao invés de se contentar com a transmissão de soluções já prontas (PIAGET, 1977, p. 18).

Como pode ser verificado na passagem que segue, Piaget (1977) deixa claro que as aprendizagens realizadas pelo indivíduo são qualitativamente superiores àquelas em que há a interferência do professor. $\mathrm{O}$ importante é desenvolver um método (o aprender a aprender) que se mostre útil na vida do indivíduo, e não se apropriar do conteúdo historicamente acumulado.

Conquistar por si mesmo um certo saber, com a realização de pesquisas livres, e por meio de um esforço espontâneo, levará a retê-lo muito mais; isso possibilitará sobretudo a aquisição de um método que lhe será útil por toda a vida e aumentará permanentemente a sua curiosidade, sem o risco de estancá-la; quanto mais não seja, ao invés de deixar que a memória prevaleça sobre o raciocínio, ou subverter a inteligência a exercícios impostos de fora, aprenderá ele a fazer por si mesmo funcionar a sua razão e construirá livremente suas próprias noções (PIAGET, 1977, p. 62, grifos nossos).

Piaget (1977) continua sua exposição, em que fica ainda mais clara a ideia de que a função precípua da escola consiste em assegurar a adaptação do indivíduo à vida social, ideia que tem clara vinculação com a filosofia pragmatista:

Afirmar o direito da pessoa humana à educação é, pois, assumir uma responsabilidade muito mais pesada que a de assegurar a cada um a possibilidade de leitura, escrita e cálculo: significa, a rigor, garantir a toda criança o pleno desenvolvimento de suas funções mentais e a aquisição dos conhecimentos, bem como dos valores morais que correspondem ao exercício destas funções, até a adaptação à vida social atual [...] do nascimento até o fim da adolescência a educação [...] constitui um dos dois fatores fundamentais necessários à formação intelectual e moral, de tal forma que a escola fica com boa parte da responsabilidade no que diz respeito ao sucesso ou ao fracasso do indivíduo, na realização de suas próprias possibilidades e em sua adaptação à vida social (PIAGET, 1977, p. 40-41, grifos nossos). 
A teoria construtivista é o pilar da pedagogia das competências, que, por sua vez, é um importante conceito da teoria do professor reflexivo, como procuraremos mostrar ao longo desta exposição.

\subsection{Pedagogia das competências}

Os dois principais representantes e propositores da Pedagogia das Competências são o sociológico suíço Phillipe Perrenoud e o espanhol Juan Delval. O primeiro defende o conceito de competência como sendo "(...) uma capacidade de agir eficazmente em um determinado tipo de situação, apoiada em conhecimentos, mas sem limitar-se a eles" (PERRENOUD, 1999, p. 7). Em outra obra, Perrenoud (2005, p. 89) afirma que "As competências manifestam-se na capacidade de um sujeito de mobilizar diversos recursos cognitivos para agir com discernimento diante de situações complexas, mutáveis e sempre singulares". As competências seriam responsáveis por combinar um conjunto de esquemas mentais, tais como percepção, pensamento, avaliação e ação, que possibilitam a realização de antecipações, inferências, generalizações, etc.

Uma competência seria, então, um simples esquema? Eu diria que antes ela orquestra um conjunto de esquemas. Um esquema é uma totalidade constituída, que sustenta uma ação ou operação única, enquanto uma competência com uma certa complexidade envolve diversos esquemas de percepção, pensamento, avaliação e ação, que suportam inferências, antecipações, transposições analógicas, generalizações, apreciação de probabilidades, estabelecimento de um diagnóstico a partir de um conjunto de índices, busca de informações pertinentes, formação de uma decisão, etc. (PERRENOUD, 1999, p. 24, grifos nossos).

O ensino se organiza prioritariamente a partir das ações dos alunos sobre a realidade imediatamente vivenciada. Os conhecimentos científicos são preteridos em nome da experimentação prática e dos procedimentos de ensino. Para Perrenoud, a escola deveria se preocupar em desenvolver competências que serão úteis ao indivíduo ao longo de sua vida; portanto as competências são formadas na prática, no e pelo treinamento, e visam a resolver problemas oriundos da prática, expressando a vinculação do autor ao pragmatismo:

As competências não se ensinam, mas se constroem graças a um treinamento. [...] Para desenvolver competências, é preciso confrontar-se pessoalmente, de 
forma ao mesmo tempo repetida e variada, com situações complexas e empenhar-se para tentar dominá-las, o que, aos poucos, leva a integração dos saberes, habilidades mais estritas, informações, métodos para enfrentar, para decidir em tempo real, para assumir riscos (PERRENOUD, 2005, p. 75).

Nessa perspectiva, a escola seria apenas mais uma agência de socialização, atendendo aos interesses e às necessidades imediatas das crianças. As possibilidades de a escola promover o desenvolvimento intelectual dos estudantes não se diferenciariam qualitativamente de outros locais sociais - tanto que o desenvolvimento intelectual acontece sem a mediação daquilo que é ensinado na escola.

Em princípio, pareceria que uma das missões da escola seria a de promover o desenvolvimento intelectual dos alunos, mas na realidade não é assim. O desenvolvimento intelectual acontece independentemente da escola. Não podemos negar, no entanto, que freqüentar a escola põe o aluno em contato com um mundo de conhecimentos que lhe proporciona determinados tipos de experiências úteis. Ali realiza atividades que não realizaria fora da escola e às quais não têm acesso aqueles que não a freqüentam. Isso é indiscutível. Mas aquilo que se ensina na escola não está dirigido, fundamentalmente, a favorecer o desenvolvimento intelectual, já que este ocorre tanto na escola como fora dela, mas sobretudo com independência do que lhe é ensinado (DELVAL, 1988, p. 26, grifos nossos).

Essa perspectiva teórica também expressa, de forma clara, o processo de secundarização do conhecimento científico, evidenciando a clara defesa do irracionalismo na educação. Perrenoud (2005, p. 54) afirma que “(...) é preciso abrir mão de dois terços das noções ensinadas, ir ao essencial, para construí-lo mais lentamente, progressivamente, dialeticamente, no tateio, na busca e no debate". A redução do ensino de conteúdos escolares se justifica, para Perrenoud (2005), pelo fato de que não há aplicabilidade pragmática do conhecimento aprendido na escola em situações do dia a dia. Essa ideia já se faz presente nos escritos de Dewey (1959b), que afirma que a informação tem importância no processo educativo, desde que ela possa ser aplicada pelo educando em uma situação prática: "O cabedal de coisas ouvidas ou lidas tem importância - e quanto maior for, melhor - mas somente se o educando dele necessitar e o puder aplicar em alguma situação dele, educando" (DEWEY, 1959b, p. 206, grifos do autor).

$\mathrm{Na}$ formação por competências, qual o papel do professor? "Os professores devem parar de pensar que dar o curso é o cerne da profis- 
são. Ensinar hoje deveria ser conceber, encaixar e regular situações de aprendizagem, seguindo os princípios pedagógicos ativos construtivistas" (PERRENOUD, 2000, on-line). Destarte, em síntese, para a pedagogia das competências, mais importante que aprender é treinar competências úteis para o desenvolvimento de habilidades, a fim de habilitar o indivíduo para a realização de tarefas específicas no interior do processo produtivo, atendendo, assim, à lógica do capital.

\subsection{Teoria do professor reflexivo}

A teoria do professor reflexivo traz a perspectiva e os postulados do aprender a aprender para o campo da formação do professor. Tardif (2000), representante dessa tendência, postula que os cursos de formação universitária não têm desempenhado adequadamente seu papel no que se refere à formação profissional, e que isso se deve à sua centralidade no saber teórico ou científico. O autor propõe então a substituição dessa formação pela epistemologia da prática profissional, que preconiza o rompimento com os conbecimentos disciplinares e a implementação de uma formação centrada nos saberes cotidianos dos professores. $\mathrm{O}$ mesmo autor defende ainda que a resolução de situações únicas e instáveis da vida cotidiana não deve ser realizada pela mediação do conhecimento científico, já essa modalidade de conhecimento ofereceria técnicas padronizadas e uma resposta pronta, o que seria incoerente com a proposta de construção do próprio conhecimento.

No que se refere especificamente ao trabalho do professor, Tardif (2002) preconiza que os saberes docentes são, em grande medida, originados nas experiências escolares e familiares, engendrando crenças, representações e certezas sobre a atividade docente, bem como sobre o aluno. Para Tardif (2002), esse saber oriundo da experiência escolar é "muito forte", mantendo-se ao longo do tempo, de modo que "(...) a formação universitária não consegue transformá-lo nem muito menos abalá-lo" (TARDIF, 2002, p. 20, grifos nossos). Aqui cabe questionarmos: a defesa deste ideário não estaria colocando em xeque a existência da universidade e, em consequência, do professor e do conhecimento científico?

Nessa direção, ações sem objetivo prévio, regidas pela causalidade e pela intuição, assim como o não-saber na atividade docente, deixam de ser compreendidas como questões a serem superadas com base na mediação de uma teoria pedagógica rica e consistente, que possibilite 
explicar cientificamente a realidade. Ao contrário, o não-saber docente e o uso de ações apoiadas no improviso são naturalizados e passam a ser condição para que a atividade educativa esteja em sintonia com as novas tendências educacionais, promovendo a clara defesa da irracionalidade científica, como se pode verificar na passagem que segue:

A racionalidade é ilusória quando se finge acreditar que processos tão complexos quanto o pensamento, a aprendizagem e a relação podem ser inteiramente dominados sem que haja uma erupção de valores, da subjetividade, da afetividade, sem que haja dependência relativamente a interesses, preconceitos, incompetências de uns e de outros. É freqüente a formação sugerir que tudo pode ser dominado quando se é um bom profissional, mas uma profissão impossível - como Freud denominava a profissão docente -, o profissional "dá o seu melhor" tendo de aceitar com alguma humildade que não domina os processos e que, portanto, o acaso e a intuição desempenham um papel em grande parte dos êxitos e dos fracassos (PERRENOUD, 1993 p. 31).

Diante do exposto até aqui, indagamos: quais seriam os reais avanços dessas novas pedagogias, ditas inovadoras? Elas resolveram a dicotomia entre teoria e prática ou a tornaram ainda mais insolúvel? O próprio Tardif (2002) oferece elementos importantes para responder a essas questões, ao defender que a escola se converteria em um mercado em que pais, alunos e adultos - os últimos, em processo de formação continuada - buscariam o "saber-fazer" que os tornaria aptos e adaptáveis à lógica capitalista.

A instituição escolar deixaria de ser um lugar de formação para tornar-se um mercado onde seriam oferecidos, aos consumidores (alunos e pais, adultos em processo de reciclagem, educação permanente), saberes instrumentados, saberes-meios, um capital de informações mais ou menos úteis para o seu futuro "posicionamento" no mercado de trabalho e sua adaptação à vida social. As clientelas escolares se transformariam em clientes. A definição e a seleção dos saberes escolares dependeriam então das pressões dos consumidores e da evolução mais ou menos tortuosa do mercado dos saberes sociais. A função dos professores não consistiria mais em formar indivíduos, mas em equipá-los tendo em vista a concorrência implacável que rege o mercado de trabalho (TARDIF, 2002, p. 47-48, grifos nossos).

Os saberes necessários, engendrados pelas pedagogias do aprender a aprender, são, destarte, aqueles requeridos pelo sistema capitalista para que os membros da classe trabalhadora sejam capazes de atender 
adequadamente às demandas do processo produtivo, adaptando-se às novas necessidades tecnológicas e às operações a serem desempenhadas no trabalho. Portanto, para essa perspectiva teórica, a educação escolar deveria abandonar o objetivo de formar indivíduos que sabem algo, limitando-se a formar, guiados pelo pragmatismo, indivíduos predispostos a aprender aquilo que possa se mostrar útil em seu processo de adaptação à ordem social, culminando em um quase completo esvaziamento do ensino escolar. Como consequência, “(...) ratifica-se a cotidianidade do contexto escolar, a ter como cruel conseqüência (não considerada por estas 'novas teorias') o 'analfabetismo histórico, político e conceitual”' (MANACORDA, 1989 apud MARTINS, 2001).

Diante do exposto até aqui, o leitor poderia se questionar: por

que, historicamente, esse tipo de educação que dissocia a teoria da prática é o hegemônico? Por que a sociedade capitalista demanda esse tipo de proposta educacional? Kuenzer (2007) responde a essa questão, afirmando que a dicotomia entre teoria e prática é a base sobre a qual se organiza o próprio sistema econômico vigente, qual seja, o fato de a classe dominante deter a propriedade privada dos meios de produção e de a classe dominada ter apenas sua força de trabalho como mercadoria a ser vendida para o capitalista, como garantia de sua subsistência.

\section{A psicologia materialista-histórica e dialética de A. N. Leontiev}

Contrapondo-se ao primado da experiência para o desenvolvimento psíquico, a psicologia de A. N. Leontiev preconiza que o conhecimento não é construído na e pela experiência - como preconizam o ideário escolanovista, construtivista e, mais recentemente, os defensores contemporâneos do ideário do aprender a aprender, como Tardif (2000; 2002) e Perrenoud (1993; 1999; 2005), mas é historicamente elaborado e se encontra objetivado, depositado nas produções humanas, sejam elas materiais ou intelectuais.

De acordo com o psicólogo soviético, o processo de ensinoaprendizagem deve visar à reprodução, nos alunos, das aptidões humanas formadas ao longo da história pelas gerações precedentes, permitindo a cada indivíduo singular apropriar-se da riqueza humano-genérica. Nessa direção, no prólogo do livro Psicologia da Arte, Leontiev (1970) sintetiza a 
compreensão vigotskiana da obra literária, esclarecendo que o autor faz uso do termo "catarse" de forma distinta da empregada por Freud. Vigotski entende que, na obra de arte, não haveria uma mera manifestação de tendências afetivas reprimidas, mas ela expressaria “(...) a solução de certos problemas da personalidade, o descobrimento de uma verdade mais humana, mais elevada, dos fenômenos e situações da vida" (LEONTIEV, 1970, p. 11, grifos nossos). A fruição (ou recepção) da obra de arte possibilita ao indivíduo experienciar sentimentos e vivenciar coisas que sua vida cotidiana normalmente não lhe permite. Assim, o autor não deixa dúvidas sobre o tipo de educação que as crianças devem receber: aquela que engendra a ampliação dos horizontes culturais dos alunos, mediante a apropriação da riqueza humano-genérica objetivada nos conteúdos escolares. Leontiev (1978) evidencia aqui os limites da experiência para o processo de desenvolvimento humano:

Está fora de questão que a experiência individual de um homem, por mais rica que seja, baste para produzir a formação de um pensamento lógico ou matemático abstrato e sistemas conceituais correspondentes. Seria preciso não uma vida, mas mil. De fato, o mesmo pensamento e o saber de uma geração formam-se a partir da apropriação dos resultados da atividade cognitiva das gerações precedentes (LEONTIEV, 1978, p. 266).

Há aqui uma evidente contraposição à ideia, hegemônica na atualidade, de que a formação das novas gerações deveria ser orientada pela adesão a uma "utopia praticista", na qual basta "saber fazer" (MORAES, 2004).

Outra divergência entre esse referencial teórico e os apresentados anteriormente refere-se ao papel do professor no processo de ensinoaprendizagem: a apropriação do conhecimento científico, filosófico e artístico não se dá de forma espontânea e direta, tampouco o papel do professor se restringe ao de um "animador"; ao contrário, o professor é um mediador entre o aluno e o conhecimento científico, e essa relação é privilegiada para engendrar mudanças substanciais no psiquismo dos alunos. Leontiev afirma que as operações mentais apenas surgem “(...) sob a influência do ensino que dirige de maneira específica a atividade da criança, que organiza as suas ações" (LEONTIEV, 2005, p. 67). Compara o desenvolvimento de crianças que não tiveram acesso à instrução dos adultos ao daquelas de mesma idade “(...) mais afortunadas, 'cuja mão é guia- 
da pela razão", denunciando o atraso no processo de desenvolvimento das primeiras em relação às segundas, exatamente em função de não se apropriarem do processo de aprendizagem.

No que se refere aos processos de desenvolvimento e aprendizagem, a psicologia histórico-cultural também parte de uma premissa fundamentalmente oposta à do ideário do aprender a aprender: se, para as últimas, é o desenvolvimento que engendra a aprendizagem, para a primeira, é a aprendizagem que impulsiona o desenvolvimento. A educação escolar não "espera" pelo desenvolvimento das funções psíquicas, mas condiciona seu desenvolvimento, por meio do processo de aprendizagem. Além disso, nessa perspectiva, o ensino deve ser organizado tendo em vista que a escola dirige o ensino não para etapas intelectuais já alcançadas, mas, sim, para estágios de desenvolvimento ainda não incorporados pelos alunos, funcionando como um motor de novas conquistas intelectuais, por um lado, não se restringindo ao que o aluno já sabe e, por outro lado, não indo além daquilo que ele é incapaz de fazer, mesmo com auxílio.

Entende-se que há outra diferença fundamental entre os postulados de Leontiev e o ideário das pedagogias do aprender a aprender, qual seja, o papel do conhecimento no desenvolvimento humano. Para as últimas, a apropriação do conteúdo escolar é, no limite, capaz apenas de ocupar desnecessariamente a memória dos estudantes (BLOCH, 1951; DEWEY, 1959a), um fardo que inutilmente carregam, ou ainda, verdades que não devem ser transmitidas pelo professor, mas construídas pelos alunos (PIAGET, 1977).

Contrapondo-se a tais ideias, Leontiev (1978) afirma que, na sociedade capitalista, o que se verifica é a impossibilidade de cada indivíduo ter acesso ao patrimônio humano-genérico, o que caracteriza o fenômeno da alienação, definida como “(...) uma ruptura entre, por um lado, as gigantescas possibilidades desenvolvidas pelo homem e, por outro, a pobreza e a estreiteza de desenvolvimento que, se bem que em graus diferentes, é a parte que cabe aos homens concretos" (LEONTIEV, 1978, p. 280). Em outras palavras, o ser humano, a humanidade, vem enriquecendo-se ao longo da história, mas isso não se traduz em enriquecimento da vida de todos os homens. As pessoas, na sua grande maioria, vivem em condições muito aquém daquilo já alcançado pelo gênero humano em termos do seu enriquecimento. Desse modo, as possibilidades para a humanização dos indivíduos em uma sociedade de classes devem ser pensadas a partir do lugar que eles ocupam nas relações sociais. 
O processo de distanciamento e conflito entre a riqueza material e intelectual do ser humano e a vida de cada pessoa é, portanto, um dos temas centrais da análise de Leontiev (1978). Em uma sociedade não alienada, ou seja, uma sociedade comunista, a educação do novo homem deve assegurar a ele um desenvolvimento multilateral, de modo que cada indivíduo possa se apropriar das mais elevadas e diversificadas objetivações humanas, o que lhe assegurará sua plena humanização (DUARTE, 2004). Assim, diferentemente do que preconizam as pedagogias do aprender a aprender, é a apropriação da atividade material e intelectual humana acumulada nos objetos da cultura que possibilita a humanização do indivíduo. Além disso, para Leontiev (1978), a apropriação da cultura tem papel determinante no desenvolvimento psíquico das novas gerações, tanto no desenvolvimento das funções psicológicas superiores ${ }^{3}$ quanto no engendramento de novas formações mentais, ou seja, a constituição de formações cerebrais autenticamente novas em comparação com o cérebro do recém-nascido. A formação desses órgãos funcionais cerebrais se dá na e pela atividade do indivíduo e é, de acordo com Leontiev (1967), o princípio mais importante do desenvolvimento infantil. Esses órgãos não são inatos, mas “(...) constituem o substrato material das aptidões e funções específicas que se formam no decurso da apropriação pelo homem do mundo dos objetos e fenômenos criados pela humanidade, isto é, da cultura" (LEONTIEV, 1978, p. 271, grifos nossos). Vale ressaltar que eles atuam da mesma forma que os órgãos habituais, de morfologia constante.

Além disso, na psicologia histórico-cultural, o indivíduo e a sociedade são formados dialeticamente: apropriando-se da cultura humana, o indivíduo se humaniza, ao mesmo tempo que, por meio de suas ações na realidade, dá continuidade a uma existência eminentemente histórico-social. Destarte, essa perspectiva não compactua com pressupostos naturalizantes e biologizantes preconizadas por Dewey e pelos defensores das pedagogias do aprender a aprender. Em diferentes passagens, Leontiev (1978) enfatiza que o processo de apropriação em nada se assemelha ao de adaptação biológica, já que o último remete à transformação das propriedades do organismo e da espécie, enquanto o primeiro visa à reprodução das faculdades especificamente humanas e historicamente formadas na e pela atividade vital humana, o trabalho.

A exemplo dos filósofos marxistas (MARX; ENGELS, 1986; MARX, 2004; LUKÁCS, 2004), Leontiev (1978) atribui lugar central ao 
conceito de trabalho em suas obras, por ver nele o próprio processo de produção do homem. Por meio do trabalho, ele (o homem) desprendeuse da natureza, diferenciou-se dela, elevou-se acima dos seus limites e passou a exercer sobre ela uma ação transformadora; portanto não há, nessa perspectiva teórica, continuidade entre homem e natureza, mas, sim, um processo de superação por incorporação. O homem é parte da natureza, mas, dialeticamente, luta para superá-la. Em outras palavras, a relação com a natureza é fundamental não porque o homem continua a ser membro da natureza, mas porque luta contra ela. Ao longo dessa luta, o homem extrai da natureza o de que precisa para sobreviver, bem como o que necessita para ultrapassar uma vida simplesmente natural. Como se opera esse salto? No e pelo trabalho, por meio do emprego de instrumentos de trabalho e da organização do trabalho. Nesse sentido, Lukács (2004) demonstra que no trabalho estão os elementos constitutivos do ser social:

Só o trabalho (...) possibilita ao próprio homem que trabalha a transição do ser meramente biológico ao ser social. (...) No trabalho se encontram contidas in nuce $e^{4}$ todas as determinações que, tal como veremos, constituem a essência do novo dentro do ser social. O trabalho pode ser considerado, pois, como fenômeno originário, como modelo do ser social (LUKÁCS, 2004, p. 58-59).

Por meio do desenvolvimento da atividade produtiva foi possível ao homem o salto ontológico ${ }^{5}$ do biológico ao sócio-histórico (LEONTIEV, 1978), ou seja, das formas pré-humanas para o ser social, marcando definitivamente o rompimento no modo de funcionamento do psiquismo humano em relação aos outros animais. O ser humano altera o mundo externo pelo uso de instrumentos e da linguagem e, dialeticamente, a relação inversa também se estabelece: os símbolos e os objetos criados pelo homem acabam por modificar seu psiquismo e seu comportamento.

Leontiev (1978) tece uma severa crítica aos fundamentos filosóficos pragmáticos e seu desdobramento na forma de uma concepção biologizante do homem e da sociedade, conforme se pode verificar na passagem que segue:

Se realmente a vida se reduz, para o homem, em efetuar atos cujo único fim é a sobrevivência, devemos admitir que o fundamento supremo do comportamento é a sua utilidade. O êxito, o efeito positivo, é nesta ótica o único cri- 
tério de adequação e de justeza: só é justo e verdadeiro o que conduz ao sucesso. Aqui reside a tese de todo o pragmatismo. O utilitarismo e o pragmatismo são conseqüência necessária da transferência mecânica, para o homem, das relações biológicas; com efeito, os animais são realmente "pragmáticos práticos", no sentido em que a regulação de seu comportamento não tem outro fundamento a não ser a utilidade biológica. Mas eles não têm que resolver os problemas que se põe ao homem e à humanidade. A démarche naturalista torna impossivel a explicação científica da verdadeira especificidade da atividade e da consciência humanas; mas, por outro lado, reforça retrospectivamente as concepcões erradas em biologia (LEONTIEV, 1978, p. 147-148, grifos nossos).

Entendemos que as críticas de Leontiev (1978) aos fundamentos pragmáticos e naturalizantes podem ser aplicadas ao ideário do aprender a aprender, uma vez que Dewey (1959a; 1959b) Piaget (1988a; 1988b; 1977) Perrenoud (1993; 1999; 2005) e Tardif (2000; 2002) se utilizam dessa concepção filosófica. Como desdobramento, verifica-se, no âmbito do trabalho, uma atividade esvaziada de sentido, já que só visa à reprodução do trabalhador enquanto tal, portanto é uma atividade geradora de alienação (MARX, 2004), contrapondo-se à sua plena humanização. No âmbito educacional, a sedutora proposição do "aprender fazendo" é largamente empregada, em detrimento do ensino dos conhecimentos científicos - mediador capaz de promover um salto qualitativo no desenvolvimento psicológico dos educandos.

\section{3. À guisa de conclusão}

À luz do materialismo histórico e dialético, é possível verificarmos que as pedagogias do aprender a aprender se revigoram através dos tempos não por opções individuais, mas, fundamentalmente, pelas relações produtivas envolvidas nesta sociedade e, em essência, dão continuidade ao projeto educacional iniciado por Dewey (1959a; 1959b) há 50 anos. Tal empreitada não mostra sinais de envelhecimento; ao contrário, se fortalece na produção de Piaget (1988a; 1988b; 1977) e, mais recentemente, de Tardif (2000; 2002) e Perrenoud (1993; 1999; 2005).

Em nosso entender, a teoria de Leontiev, cujas bases filosóficas encontram-se no materialismo histórico e dialético, fornece elementos para o enfrentamento do processo de esvaziamento dos conteúdos escolares e do trabalho do professor, na medida em que essa produção evidencia a necessidade de superação do pragmatismo e do irracionalismo na 
educação e, mais do que isso, defende a superação do sistema econômico capitalista, o que oportunizaria o acesso ao desenvolvimento multilateral dos educandos:

Só a supressão do reino da propriedade privada e das relações antagonistas que ela engendra pode pôr fim à necessidade de um desenvolvimento parcial e unilateral dos indivíduos. Só ela cria, com efeito, as condições em que o princípio fundamental da ontogênese humana - a saber, a reprodução nas aptidões e propriedades do indivíduo, das aptidões e propriedades múltiplas formadas durante o processo sócio-histórico - se pode plenamente exercer (LEONTIEV, 1978, p. 174).

No que se refere às apropriações contemporâneas das obras dos autores de Leontiev, vários pesquisadores (DUARTE, 2001; TULESKI, 2002; FACCI, 2004; ROSSLER, 2006; MARTINS, 2001) já deram importantes contribuições a fim de demonstrar a impossibilidade de junções entre as produções da psicologia histórico-cultural, caracterizadas pelo caráter eminentemente materialista histórico-dialético e comprometidas com a superação do modo de produção capitalista, e as outras correntes psicológicas e pedagógicas que não compartilham desse referencial filosófico, tal como o ideário do aprender a aprender. Entretanto, a ampla difusão da perspectiva histórico-cultural dissociada de seus fundamentos filosóficos nos indica que ainda é necessário somar forças para denunciar esse processo.

Leontiev (1978) demonstrou consonância com a proposição vigotskiana sobre a criação de uma psicologia geral ${ }^{6}$, orientada pelo método materialista-histórico e dialético, como única forma de sair da crise na qual a ciência psicológica se encontrava (e ainda se encontra). Além disso, ele se contrapôs, de forma clara, às junções e aproximações ecléticas com teorias psicológicas cujos fundamentos filosóficos são opostos:

(...) não se pode resolver, radicalmente, o problema e superar a dualidade da psicologia tentando complexificar e enriquecer estes conceitos para os aplicar ao homem, integrando, por exemplo, o índice de atividade no conceito de adaptação ou a qualidade de sociabilidade, de caráter de classe e de atividade (aqui, ações educativas orientadas para os indivíduos) no conceito de meio, etc. esta dualidade tornou-se um hábito tal que, em artigo relativamente recente, consagrado às discussões em psicologia, se tentou justificar teoricamente a divisão dos problemas psicológicos em duas espécies: os problemas estudados na base da doutrina pavloviana e os problemas estudados na base 
do materialismo histórico. Evidentemente que a verdadeira tarefa da psicologia consiste, pelo contrário, em aplicar uma démarche única a todos os problemas da psicologia humana e inseri-los assim num sistema unificado da ciência. Esta tarefa é hoje de grande atualidade, segundo penso, pois se renunciássemos a ela criaríamos em psicologia as condições favoráveis ao desenvolvimento de todas as tendências que apóiam objetivamente as concepções naturalistas positivistas (LEONTIEV, 1978, p. 157-158).

Aproximações entre os autores da Escola de Vigotski e outras abordagens cujos fundamentos teórico-metodológicos são opostos terminam por comprometer a compreensão do leitor sobre o que esses psicólogos propunham, tanto no sentido psicológico e pedagógico propriamente dito, esvaziando as possibilidades de contribuição da psicologia histórico-cultural para os estudos e intervenções nas áreas da Educação e da Psicologia da Educação, quanto em sentido mais amplo, afastando tais produções dos pressupostos que visam à superação da sociedade capitalista e aproximando-as de ideologias que legitimam esse modo de produção (DUARTE, 2001). Diante disso, destacamos a necessidade de maiores estudos que primem por resgatar os fundamentos filosóficos que dão base aos conceitos de cada autor. Entendemos que somente assim será possível sair do pântano teórico, ou seja, esclarecer as imprecisões e confusões teóricas vigentes na ciência psicológica na atualidade.

\section{Notas}

${ }^{1}$ Piaget (1977) faz uma severa crítica ao ensino por meio da transmissão de conteúdos por parte do professor: "A experiência é com frequência prejudicada pelo fato de que, embora seja 'moderno' o conteúdo ensinado, a maneira de o apresentar permanece às vezes arcaica do ponto de vista psicológico, enquanto fundamentada na simples transmissão de conhecimentos, mesmo que se tente adotar (e de forma bastante precocemente, do ponto de vista da maneira de raciocinar dos alunos) uma forma axiomática" (PIAGET, 1977, p. 19).

${ }^{2}$ Aqui, ressaltamos a pertinência do estudo de Rossler (2006) sobre a sedução do ideário construtivista, dando a devida atenção aos capítulos I e II, nos quais o autor articula elementos centrais da Teoria do Cotidiano de Agnes Heller, buscando explicitar as formas de pensamento, sentimento e ação cotidianas que constituem um psiquismo também cotidiano, alienado, pois cristalizado na esfera da vida cotidiana. O autor demonstra que o poder de sedução do ideário construtivista encontra-se em “(...) sua aproximação a elementos fortemente difundidos no cotidiano alienado da nossa sociedade, isto é, advém do fato de este ideário reproduzir em seu discurso determinados temas e valores presentes no âmbito ideológico da sociedade contemporânea” (ROSSLER, 2006, p. 23). 
Pelos limites deste estudo, não será possível aprofundar tal discussão, o que pretendemos fazer em produções posteriores.

${ }^{3}$ Não são processos meramente endógenos, mas dependem fundamentalmente da apropriação dos signos da cultura, possibilitada pela constante mediação de outros homens. ${ }^{4}$ Em gérmen.

${ }^{5}$ Lukács (2004, p. 60-61) esclarece que "cada salto significa uma transformação qualitativa e estrutural no ser, no qual o estado inicial contém dentro de si, sem dúvida, determinadas condições e possibilidades da [forma] posterior e mais elevada, mas estas não podem ser desenvolvidas a partir daquelas segundo uma continuidade sempre retilínea. Esta ruptura com a continuidade normal da evolução é o que constitui a essência do salto, não o surgimento temporalmente súbito ou paulatino de uma nova forma de ser". O autor remete ao texto "Humanização do Macaco pelo Trabalho", de autoria de Engels (1976), para ressaltar que essa transição foi extremamente prolongada e que a linguagem e a socialização são derivações ontológicas do processo de trabalho.

${ }^{6}$ Não é possível, nos limites deste artigo, aprofundar esta questão. Isso pode ser feito mediante a leitura do texto "O significado histórico da crise da psicologia", escrito por Vigotski (1999).

\section{Referências bibliográficas}

ANTUNES, R. Aonde vai o mundo do trabalho? In: GOGGIOLA, O. (Org.). Globalização e socialismo. São Paulo: Xamã, 1997. p. 61-72.

ANTUNES, R. Trabalho e superfluidade. In: LOMBARDI, J. C.; SAVIANI, D., et al. (Orgs.). Capitalismo, trabalho e educação. Campinhas: HISTEDBR, 2002. p. 35-44.

ANTUNES, R. Os sentidos do trabalho: ensaio sobre a afirmação e a negação do trabalho. São Paulo: Boitempo, 2005a.

ANTUNES, R. Adeus ao trabalho? Ensaio sobre as metamorfoses e a centralidade. Campinas: Cortez, 2005b.

BRASIL. Diretrizes Curriculares Nacionais para a Formação de Professores da Educação Básica. Parecer CNE/CP n. 09/2001: Conselho Nacional de Educação, 2002a.

BRASIL. Referenciais para Formação de Professores. MEC/SEF: Ministério da Educação. Secretaria da Educação Fundamental, 2002b.

BLOCH, M. A. Filosofia da educação nova. São Paulo: Companhia Editora Nacional, 1951. DELORS, J. Educação: um tesouro a descobrir - Relatório para a UNESCO da Comissão Internacional sobre Educação para o século XXI. Cortez: São Paulo, 1998.

DELVAL, J. Aprender a aprender. 7 ed. Campinas: Papirus, 1998.

DEWEY, J. Como pensamos. São Paulo: Editora Nacional, 1959a.

DEWEY, J. Democracia e Educação. Introdução à filosofia da educação. 3 ed. São Paulo: Companhia Editora Nacional, 1959b.

DEWEY, J. Experiência e educação. São Paulo: Editora Nacional, 1976.

DUARTE, N. Vigotski e o aprender a aprender: crítica às apropriações neoliberais e pósmodernas da teoria vigotskiana. Campinas: Autores Associados, 2001.

DUARTE, N. Formação do indivíduo, consciência e alienação: o ser humano na psico- 
logia de A. N. Leontiev. Cad. CEDES, v. 24, n. 62, p. 44-63, abr. 2004.

EIDT, N. M. A Educação escolar e a relação entre o desenvolvimento do pensamento e a apropriação da cultura: a psicologia de A. N. Leontiev como referência nuclear de análise. Tese (Doutorado), 256p, Universidade Estadual Paulista Júlio de Mesquita Filho, 2009.

FACCI, M. G. D. Valorização on esvaziamento do trabalho do professor? Um estudo críticocomparativo da teoria do professor reflexivo, do construtivismo e da psicologia vigotskiana. Campinas, SP: Autores Associados, 2004.

GENTILE, P.; BENCINI, R. Construindo competências: Entrevista com Philippe Perrenoud, Universidade de Genebra. Nova Escola (Brasil), setembro de 2000, p. 19-31. Disponível

em: <http://www.unige.ch/fapse/SSE/teachers/perrenoud/php_main/php_2000/2000_3 1.html>. Acessado em março de 2006.

GRAMSCI, A. Americanismo e fordismo. Cadernos do Cárcere. Rio de Janeiro: Civilização Brasileira, 2001. p. 273-282. v. 4

KUENZER, A. Z. Da dualidade assumida à dualidade negada: o discurso da flexibilização justifica a inclusão excludente. Educação e Sociedade, n. 28, p. 1153-1178, 2007.

LEONTIEV, A. N. Sobre la formacion de las aptitudes. In: LEONTIEV, A. N. e OUTROS, (Orgs.). El hombre y la cultura: problemas teóricos sobre la educacion. Argentina: Editorial Grijalbo, 1967. p. 51-71.

LEONTIEV, A. N. Prólogo. In: VIGOTSKI, L. S. Psicologia del arte. Barcelona: Barral Editores, 1970. p. 7-12.

LEONTIEV, A. N. O desenvolvimento do psiquismo. Lisboa: Livros Horizonte, 1978.

LEONTIEV, A. N. Os princípios do desenvolvimento mental e o problema do atraso mental. In: LURIA, A. R; LEONTIEV, A.; VYGOTSKY, L. S. (Orgs.). Psicologia e Pedagogia: Bases psicológicas da aprendizagem e do desenvolvimento. São Paulo: Centauro, 2005. p. 59-76.

LUKÁCS, G. Ontologia del ser social: El trabajo. Buenos Aires: Herramienta, 2004.

MARTINS, L. M. Análise do processo de personalização de professores. Tese (Doutorado), 276 f., Faculdade de Filosofia e Ciências, Universidade Estadual Paulista, Marília, 2001.

MARX, K. Manuscritos econômico-filosóficos. São Paulo: Boitempo, 2004.

MARX, K.; ENGELS, F. A Ideologia Alemã. São Paulo: Hucitec, 1986.

MERLO, Á. R. C.; LAPIS, N. L. A saúde e os processos de trabalho no capitalismo: reflexões na interface da psicodinâmica do trabalho e da sociologia do trabalho. Psicologia \& Sociedade, v. 19, n. 1, p. 61-68, 2007.

MORAES, M. C. M. de. O renovado conservadorismo da agenda pós-moderna. Cadernos de Pesquisa, v. 34, n. 122, p. 337-357, maio/ago. 2004.

MIRANDA, M. G. de. Novo paradigma de conhecimento e políticas educacionais na América Latina. Cad. Pesq., n. 100, p. 37-48, mar. 1997.

NAGEL, L. Transformações históricas e processos educativos. II Congresso Brasileiro de História da Educação: História e memória da educação brasileira. SBHE. Anais do II Congresso Brasileiro de História da Educação, NATAL/RN, p. 412-423, 2002.

PERRENOUD, P. Práticas pedagógicas, profissão docente e formação. Lisboa: Dom Quixote, 1993. PERRENOUD, P. Construir as competências desde a escola. Porto Alegre: Artmed, 1999. PERRENOUD, P. Escola e cidadania: o papel da escola na formação para a democracia. Porto Alegre: Artmed, 2005. 
PIAGET, J. Para onde vai a educação? Rio de Janeiro: José Olympio, 1977.

PIAGET, J. Observações psicológicas sobre o self-government. In: PARRAT, S.; TRYPHON, A. (Orgs). Sobre a Pedagogia: Textos inéditos. São Paulo: Casa do Psicólogo, 1998a. p. 113-130.

PIAGET, J. A evolução social e a pedagogia nova. In: PARRAT, S.; TRYPHON, A. (Orgs.). Sobre a Pedagogia: Textos inéditos. São Paulo: Casa do Psicólogo, 1998b. p. 97-111. ROSSLER, J. H. Sedução e alienação no discurso construtivista. Campinas, SP: Autores Associados, 2006.

SAVIANI, D. As concep̧ões pedagógicas na bistória da educação brasileira. O espaço acadêmico da pedagogia no Brasil, 2005. Disponível em: <www.histedbr.fae.unicamp.br/navegando/artigos_frames/artigo_036.html>. Acessado em: outubro de 2007.

SAUL, R. P. As raízes renegadas da teoria do capital humano. Sociologias, v. 12, p. 230-273, 2004.

SOUZA, T. M S. Emoções e capital: As mulheres no novo padrão de acumulação capitalista. Tese (Doutorado em Psicologia Social), Pontifícia Universidade Católica de São Paulo, 2006.

TARDIF, M. Saberes profissionais dos professores e conhecimentos universitários: elementos para uma epistemologia da prática profissional dos professores e suas conseqüências em relação à formação para o magistério. Revista Brasileira de Educação, v. 13, p. 5-24, 2000.

TARDIF, M. Saberes docentes e formação profissional. 7 ed. Petrópolis: Vozes, 2002.

TONET, I. Educação, cidadania e emancipação humana. Ijuí: Ed. Unijuí, 2005.

TULESKI, S. C. Vygotski: A construção de uma psicologia marxista. Maringá: EDUEM, 2002.

VIGOTSKI, L. S. O significado histórico da crise da psicologia. Uma investigação metodológica. In: VIGOTSKI, L. S. Teoria e Método em Psicologia. São Paulo: Martins Fontes, 1999. p. 203-420.

Endereço para correspondência: Universidade Estadual Paulista Júlio de Mesquita Filho

Faculdade de Ciências de Bauru

Departamento de Psicologia

Av. Eng. Luiz Edmundo Carrijo Coube, 14-01 - Vargem Limpa 17033-360

Bauru - SP

Data de recebimento: $18 / 08 / 2008$

Data de aprovação: 10/11/2009 